EPIDEMIOLOGY

\title{
Oral and inhaled corticosteroids and adrenal insufficiency: a case-control study
}

\author{
K J Mortimer, L J Tata, C J P Smith, J West, T W Harrison, A E Tattersfield, R B Hubbard

See end of article for authors' affiliations

.....................

Correspondence to: Dr K J Mortimer, Division of Respiratory Medicine, Clinical Sciences Building, Nottingham City Hospital, Nottingham NG5 1PB, UK Kevinmortimer@msn.com

Received 1 September 2005 Accepted 26 January 2006 Published Online First 3 March 2006

.....................
Background: Adrenal insufficiency, a well recognised complication of treatment with oral corticosteroids, has been described in association with inhaled corticosteroid use in over 60 case reports. The risk of adrenal insufficiency in people prescribed an oral or inhaled corticosteroid in the general population is not known. A study was undertaken to quantify the association between adrenal insufficiency and oral and inhaled corticosteroid exposure.

Methods: A case-control study was performed using computerised general practice data from The Health Improvement Network.

Results: From a cohort of 2.4 million people, 154 cases of adrenal insufficiency and 870 controls were identified. There was a dose related increased risk of adrenal insufficiency in people prescribed an oral corticosteroid with an odds ratio of $2.0(95 \% \mathrm{Cl} 1.6$ to 2.5$)$ per course of treatment per year. Adrenal insufficiency was associated with a prescription for an inhaled corticosteroid during the 90 day period before the diagnosis with an odds ratio of $3.4(95 \% \mathrm{Cl} 1.9$ to 5.9) and this effect was dose related ( $p$ for trend $<0.001)$. After adjusting for oral corticosteroid exposure, this odds ratio was reduced to $1.6(95 \% \mathrm{Cl}$ 0.8 to 3.2 ) although the dose relation remained ( $p$ for trend 0.036 ).

Conclusion: People prescribed an oral or inhaled corticosteroid are at a dose related increased risk of adrenal insufficiency although the absolute risk is small. This analysis suggests that the increased risk in people prescribed an inhaled corticosteroid is largely due to oral corticosteroid exposure, but inhaled corticosteroids may have an effect when they are taken at higher doses.
$\mathrm{T}$ he association between adrenal insufficiency and treatment with oral corticosteroids has been recognised for decades, ${ }^{1-3}$ although the magnitude of the risk has not been determined. An association with inhaled corticosteroid use came to attention more recently with five reports in the last 4 years describing 60 cases of adrenal insufficiency in people taking an inhaled corticosteroid. ${ }^{4-8}$ The majority of these cases were children, many of whom were taking high doses of an inhaled corticosteroid and over $80 \%$ were taking fluticasone propionate at the time. The risk of adrenal insufficiency among people in the general population prescribed an oral or inhaled corticosteroid is unknown. To quantify this we investigated the association between adrenal insufficiency and prescriptions for oral and inhaled corticosteroids in a case-control study using data from The Health Improvement Network (THIN) database. ${ }^{9}$

\section{METHODS}

THIN is a longitudinal database derived from computerised records of diagnostic and prescription information from general practices in the United Kingdom. The database included 2.4 million people in 177 general practices when the data were extracted in 2004. A previous audit of the THIN database has confirmed a high level of completeness of clinical diagnostic and prescribing data, confirming the usefulness of this dataset for medical research. ${ }^{9}$

\section{Case-control set}

Cases were all people with a diagnosis of adrenal insufficiency, adrenal crisis, or Addison's disease in their computerised medical records. We excluded people prescribed oral hydrocortisone because this is used almost exclusively to treat established adrenal insufficiency and we were interested in new cases. The first recorded date of adrenal insufficiency was labelled as the index date. Up to six control subjects were matched to each case by age at index date, sex, and general practice, and they had to be alive and contributing data on the date of the case's index date. Controls were allocated the same index date as their matched case.

\section{Data extraction and processing}

Data were extracted on all recorded prescriptions for oral and inhaled corticosteroids and on smoking status, body mass index, and diagnoses of asthma and chronic obstructive pulmonary disease (COPD). We calculated the median number of courses of oral corticosteroids per year (defined as the number of separate prescriptions issued for an oral corticosteroid) for cases and controls and the mean daily dose of inhaled corticosteroid for each person in the 90 days prior to the index date.

\section{Analysis of data}

Conditional logistic regression was used to quantify the association between adrenal insufficiency and at least one prescription for an oral or inhaled corticosteroid. The association between adrenal insufficiency and the number of courses of oral corticosteroids was also estimated and compared with those never prescribed an oral corticosteroid. The risk of adrenal insufficiency was estimated in those prescribed an inhaled corticosteroid within 90 days and more than 90 days prior to the index date compared with those never prescribed an inhaled corticosteroid for all drugs and for beclometasone dipropionate, budesonide, fluticasone propionate, and mometasone furoate separately. We chose 90 days to represent current or recent exposure. In addition we examined the impact of the mean daily dose of inhaled corticosteroid exposure within 90 days of the index date, grouping daily doses as follows: $1-600 \mu \mathrm{g}, 601-1200 \mu \mathrm{g}$, $>1201 \mu \mathrm{g}$. We assessed the impact of potential confounding 
Table 1 Demographic details of cases and controls

\begin{tabular}{|c|c|c|c|c|c|}
\hline & \multicolumn{2}{|c|}{ Cases $(n=154)$} & \multicolumn{2}{|c|}{ Controls ( $n=870$ ) } & \multirow[b]{2}{*}{ Odds ratio $(95 \% \mathrm{Cl})$} \\
\hline & $\mathrm{N}$ & $\%$ & $\mathrm{~N}$ & $\%$ & \\
\hline Male & 64 & 41.6 & 359 & 41.3 & Matching variable \\
\hline \multicolumn{6}{|l|}{ Age at adrenal crisis } \\
\hline$<15$ & 10 & 6.5 & 58 & 6.7 & Matching variable \\
\hline $15-24.9$ & 6 & 3.9 & 47 & 5.4 & Matching variable \\
\hline $25-34.9$ & 18 & 11.7 & 103 & 11.8 & Matching variable \\
\hline $35-44.9$ & 24 & 15.6 & 133 & 15.3 & Matching variable \\
\hline $45-54.9$ & 25 & 16.2 & 140 & 16.1 & Matching variable \\
\hline $55-64.9$ & 19 & 12.3 & 106 & 12.2 & Matching variable \\
\hline $65-74.9$ & 30 & 19.5 & 169 & 19.4 & Matching variable \\
\hline$\geqslant 75$ & 22 & 14.3 & 114 & 13.1 & \\
\hline \multicolumn{6}{|l|}{ Smoking status } \\
\hline Non-smoker & 64 & 41.6 & 282 & 32.4 & Reference \\
\hline Ex-smoker & 7 & 4.5 & 31 & 3.6 & $0.9(0.4$ to 2.3$)$ \\
\hline Current smoker & 41 & 26.6 & 225 & 25.9 & $0.8(0.5$ to 1.2$)$ \\
\hline Missing & 42 & 27.3 & 332 & 38.2 & $0.4(0.2$ to 0.7$)$ \\
\hline \multicolumn{6}{|l|}{ Body mass index $\left(\mathrm{kg} / \mathrm{m}^{2}\right)$} \\
\hline Underweight $(<18.5)$ & 5 & 3.2 & 12 & 1.4 & $2.1(0.7$ to 6.3$)$ \\
\hline Normal (18.5-24.9) & 52 & 33.8 & 233 & 26.8 & Reference \\
\hline Overweight (25.0-29.9) & 25 & 16.2 & 156 & 17.9 & $0.7(0.4$ to 1.2$)$ \\
\hline Obese $(>30)$ & 7 & 4.5 & 51 & 5.9 & $0.6(0.3$ to 1.4$)$ \\
\hline Missing & 65 & 42.2 & 418 & 48.0 & $0.6(0.4$ to 1.0$)$ \\
\hline \multicolumn{6}{|c|}{ Diagnosis of asthma or COPD } \\
\hline Asthma & 32 & 20.8 & 90 & 10.3 & 2.4 (1.5 to 3.8$)$ \\
\hline COPD & 10 & 6.5 & 27 & 3.1 & $2.2(1.0$ to 4.7$)$ \\
\hline Asthma and COPD & 5 & 3.2 & 17 & 2.0 & $1.8(0.6$ to 5.2$)$ \\
\hline
\end{tabular}

by smoking, body mass index, and oral or inhaled corticosteroids as appropriate using multivariate analyses and retaining variables that led to a change in the odds ratio (OR) of $10 \%$ or more. The analysis was carried out using Stata statistical software Release 8.0 (Stata Corp, College Station, TX, USA).

\section{RESULTS}

Two hundred and eighty nine patients with a recorded diagnosis of adrenal insufficiency were identified; 135 with a previous prescription for oral hydrocortisone were excluded, leaving 154 cases and 870 controls who contributed a median of 4.9 (IQR 2.5-8.5) years and 5.3 (IQR 2.6-8.5) years of data prior to the index date. The mean (SD) age of the cases was 53 (21) years and $64(42 \%)$ were male. Patients with adrenal insufficiency were more likely than controls to have asthma or COPD but were of similar body mass index and smoking status (table 1).
Of the cases and controls, 58 (38\%) and 59 (7\%) had been prescribed an oral corticosteroid, 31 (20\%) and 78 (9\%) had been prescribed an inhaled corticosteroid, and 92 (60\%) and $764(88 \%)$ had no recorded prescriptions for either an inhaled or oral corticosteroid. Of those prescribed an oral corticosteroid, cases and controls received a median of 2 (IQR 0.4-5.5) and 0.5 (IQR 0.2-1.2) courses of oral corticosteroid per year, respectively. Of the people prescribed an inhaled corticosteroid within 90 days of the index date (22 cases and 40 controls), the mean (SD) daily dose was 1054 (774) $\mu \mathrm{g}$ for cases and 667 (367) $\mu \mathrm{g}$ for controls (data missing for one control) in the 90 days prior to the index date. The mean (SD) daily dose of beclometasone dipropionate, budesonide, and fluticasone propionate for cases was 1116 (885) $\mu \mathrm{g}$, $444 \mu \mathrm{g}$ (based on one case) and 890 (545) $\mu \mathrm{g}$, respectively, and for controls was $678(385) \mu \mathrm{g}, 467$ (277) $\mu \mathrm{g}$ and 500 (192) $\mu \mathrm{g}$, respectively. There were no prescriptions for mometasone furoate.

Table 2 Association between individual inhaled corticosteroids and adrenal insufficiency

\begin{tabular}{|c|c|c|c|c|c|c|}
\hline \multirow{2}{*}{$\begin{array}{l}\text { ICS exposure before } \\
\text { adrenal crisis* }\end{array}$} & \multicolumn{2}{|c|}{ Cases $(n=154)$} & \multicolumn{2}{|c|}{ Controls $(n=870$ ) } & \multirow[b]{2}{*}{ OR $(95 \% \mathrm{Cl})$} & \multirow{2}{*}{$\begin{array}{l}\text { OR adjusted for OCS } \\
(95 \% \mathrm{Cl}) \ddagger\end{array}$} \\
\hline & $\overline{\mathrm{N}}$ & $\%$ & $\overline{\mathrm{N}}$ & $\%$ & & \\
\hline \multicolumn{7}{|c|}{ Any inhaled corticosteroid } \\
\hline Nevert & 123 & 79.9 & 792 & 91.0 & Reference & Reference \\
\hline$>90$ days & 9 & 5.8 & 38 & 4.4 & $1.6(0.7$ to 3.4$)$ & $1.0(0.4$ to 2.3$)$ \\
\hline$\leqslant 90$ days & 22 & 14.3 & 40 & 4.6 & $3.4(1.9$ to 5.9$)$ & $1.6(0.8$ to 3.2$)$ \\
\hline \multicolumn{7}{|l|}{ Fluticasone propionate } \\
\hline$>90$ days & 1 & 0.6 & 3 & 0.3 & $2.1(0.2$ to 20.6$)$ & $2.6(0.2$ to 28.8$)$ \\
\hline$\leqslant 90$ days & 8 & 5.2 & 4 & 0.5 & $10.4(3.1$ to 35.3$)$ & $4.6(1.3$ to 17.0$)$ \\
\hline \multicolumn{7}{|l|}{ Budesonide } \\
\hline$>90$ days & 4 & 2.6 & 14 & 1.6 & $2.0(0.6$ to 6.4$)$ & $1.4(0.4$ to 4.7$)$ \\
\hline$\leqslant 90$ days & 1 & 0.6 & 5 & 0.6 & $1.3(0.2$ to 11.5$)$ & Insufficient data \\
\hline \multicolumn{7}{|c|}{ Beclometasone dipropionate } \\
\hline$>90$ days & 12 & 7.8 & 36 & 4.1 & $2.2(1.1$ to 4.3$)$ & $1.1(0.4$ to 2.6$)$ \\
\hline$\leqslant 90$ days & 14 & 9.1 & 33 & 3.8 & $2.7(1.4$ to 5.3$)$ & $1.1(0.5$ to 2.7$)$ \\
\hline
\end{tabular}

ICS, inhaled corticosteroid; OCS, oral corticosteroid.

*At least one prescription.

†Never exposed to any inhaled corticosteroid (reference for all risk estimates).

$\ddagger$ Adjusted for number of courses of oral corticosteroids per year. 
Table 3 Association between mean daily dose of inhaled corticosteroid and adrenal insufficiency

\begin{tabular}{|c|c|c|c|c|c|c|}
\hline \multirow{2}{*}{$\begin{array}{l}\text { Mean daily dose } \\
\text { of ICS ( } \mu \mathrm{g})\end{array}$} & \multicolumn{2}{|c|}{ Cases $(n=154)$} & \multicolumn{2}{|c|}{ Controls $(n=870)^{*}$} & \multirow[b]{2}{*}{ OR $(95 \% \mathrm{Cl})$} & \multirow{2}{*}{$\begin{array}{l}\text { OR adjusted for OCS } \\
(95 \% \mathrm{Cl}) \dagger\end{array}$} \\
\hline & $\mathrm{N}$ & $\%$ & $\mathrm{~N}$ & $\%$ & & \\
\hline 0 & 132 & 85.7 & 830 & 95.4 & Reference & Reference \\
\hline$<600$ & 6 & 3.9 & 21 & 2.4 & $1.6(0.6$ to 4.1$)$ & $0.6(0.2$ to 2.3$)$ \\
\hline $600.1-1200$ & 10 & 6.5 & 15 & 1.7 & 4.6 (1.9 to 10.2 ) & 2.5 (1.0 to 6.2$)$ \\
\hline$>1200.1$ & 6 & 3.9 & 3 & 0.3 & $13.3(13.3$ to 53.9$)$ & $3.7(0.7$ to 19.2$)$ \\
\hline$p$ value for trend & & & & & $<0.001$ & 0.036 \\
\hline
\end{tabular}

ICS, inhaled corticosteroid; OCS, oral corticosteroid.

*One missing data point.

†Adjusted for number of courses of oral corticosteroids per year.

Univariate analysis showed that a prescription for at least one course of oral corticosteroids was associated with an increased risk of adrenal insufficiency with an OR of $8.6(95 \%$ CI 5.5 to 13.5). This increased risk was dose related with an OR of 2.0 (95\% CI 1.6 to 2.5 ) per course of oral corticosteroids per year. After adjusting for the mean daily dose of inhaled corticosteroid prescribed in the past 90 days, this OR was almost unchanged at 1.9 (95\% CI 1.5 to 2.4 ).

Univariate analysis also showed that at least one prescription for an inhaled corticosteroid was associated with adrenal insufficiency with an OR of 2.5 (95\% CI 1.6 to 4.0). After adjusting for the number of courses of oral corticosteroids prescribed per year as a continuous variable, this OR was reduced to 1.3 (95\% CI 0.8 to 2.3 ). Before adjusting for the impact of oral corticosteroids, a prescription for an inhaled corticosteroid within 90 days of the index date was associated with an increase in the risk of adrenal insufficiency with an OR of 3.4 (95\% CI 1.9 to 5.9) while a prescription for an inhaled corticosteroid before this time point was not associated with an increased risk (OR 1.6, 95\% CI 0.7 to 3.4 ). After adjusting for the number of courses of oral corticosteroids prescribed per year, the equivalent ORs were 1.6 (95\% CI 0.8 to 3.2 ) and 1.0 (95\% CI 0.4 to 2.3 ), respectively (table 2 ).

The increased risk of adrenal insufficiency in people taking an inhaled corticosteroid was dose related (table $3, \mathrm{p}$ for trend $<0.001$ ) and, although this relationship was attenuated, it remained significant at the $5 \%$ level after adjusting for courses of oral corticosteroids ( $p$ for trend $=0.036$ ).

The increase in risk of adrenal insufficiency differed between inhaled corticosteroids although the confidence intervals were wide and overlapped. The ORs for a prescription within 90 days of the index date for beclometasone dipropionate and fluticasone propionate after adjusting for oral corticosteroid exposure were 1.1 (95\% CI 0.5 to 2.7) and 4.6 (95\% CI 1.3 to 17.0 ), respectively; there were insufficient data for budesonide (table 2).

\section{DISCUSSION}

This is the first study to quantify the increased risk of adrenal insufficiency in people prescribed oral and inhaled corticosteroids in the general population. We found a strong doseresponse relationship between oral corticosteroid exposure and the risk of adrenal insufficiency. We also found that a prescription for an inhaled corticosteroid within 90 days of the diagnosis was associated with an increased risk of adrenal insufficiency, although this association was reduced after adjusting for oral corticosteroid exposure. This suggests that the increased risk of adrenal insufficiency associated with inhaled corticosteroid exposure was largely explained by exposure to oral corticosteroids, although we found some evidence of a persistent increase in risk with higher doses of inhaled corticosteroids and with current exposure to fluticasone propionate after adjusting for oral corticosteroid exposure.
No previous studies have assessed the effect of oral or inhaled corticosteroid use in the general population on adrenal insufficiency. By using computerised general practice data we were able to assemble enough cases of adrenal insufficiency with detailed prescription data to perform a case-control study of the impact of oral and inhaled corticosteroids on the risk of adrenal insufficiency. By matching cases to control subjects individually we have minimised confounding by age, sex and local clinical and community factors. The validity of a diagnosis of adrenal insufficiency has not been tested in computerised datasets although the validity of other clinical outcomes is known to be high. ${ }^{10}$ Although our case definition was based on a diagnosis of adrenal insufficiency, adrenal crisis, or Addison's disease in a patient's computerised records and not on specific biochemical criteria, general practitioners are unlikely to record a diagnosis of adrenal insufficiency without good supportive evidence and therefore the specificity of the diagnosis should be high. We did not have data on lifetime exposure to oral corticosteroids and so may not have adjusted our inhaled corticosteroid analyses fully for this confounding exposure, in which case our final estimates for the association between inhaled corticosteroid use and risk of adrenal insufficiency may be too high. Finally, since our data relate to prescriptions rather than actual treatment, we cannot be certain of the time scale over which treatment was actually taken. It is possible that some prescribed treatments, particularly courses of oral corticosteroids for use during an exacerbation, were never taken with the effect that exposure to such treatments was overestimated in our analysis.

Adrenal suppression as a consequence of oral corticosteroid use was recognised in the 1950s and $1960 \mathrm{~s}^{1-3}$ and became apparent when patients with asthma were weaned from oral to inhaled corticosteroids in the 1970s. ${ }^{11-14}$ The magnitude of the risk of adrenal insufficiency in people taking an oral corticosteroid is poorly characterised, however. Our study has quantified the magnitude of the risk and shown a doseresponse relationship with a doubling of the risk per course of oral corticosteroid prescribed per year. To what extent the recent use of oral corticosteroids is responsible for the increased risk or a marker of previous use of corticosteroids is uncertain.

The evidence that inhaled corticosteroids are associated with adrenal insufficiency comes mainly from case reports and case series. ${ }^{4-8}{ }^{15-23}$ The extent to which adrenal insufficiency relates to the use of oral or inhaled corticosteroids in these reports is difficult to disentangle, however, since reporting of oral corticosteroid intake is limited and may be underestimated. The survey by Todd et al provides some evidence that inhaled corticosteroids can be responsible for adrenal insufficiency since all but one of 33 cases had had less than 21 days treatment with oral corticosteroids in the year before presentation and several-including many of the children-were taking particularly high doses of inhaled corticosteroids 
An additional finding of Todd's survey was that most cases were associated with the use of fluticasone propionate. ${ }^{4}$ The largest increase in risk in our study occurred in association with a recent prescription for fluticasone propionate, although the numbers were small. The mean daily dose of fluticasone propionate in our cases was relatively high $(890 \mu \mathrm{g})$ considering that fluticasone propionate is roughly twice as potent as beclometasone dipropionate and budesonide. ${ }^{24}$ We cannot say whether high doses of fluticasone propionate were given inappropriately, because its greater potency was not appreciated, or whether it was given to people with more severe asthma, in which case the increased risk of adrenal insufficiency may be due to greater exposure to oral corticosteroids in the past. The absorption of fluticasone propionate varies considerably with lung function and this could increase the risk of systemic adverse effects in patients with good lung function. ${ }^{25}$

The main clinical finding of our study is that people prescribed an oral or inhaled corticosteroid are at a dose related increased risk of adrenal insufficiency although in absolute terms this increase is small. Our analysis suggests that exposure to oral rather than inhaled corticosteroids is the major factor explaining the association with inhaled corticosteroids, but we cannot exclude an impact of inhaled corticosteroids (particularly at higher doses) or of current exposure to fluticasone propionate. Since adrenal insufficiency is rare in the general population and may present in a non-specific way, the diagnosis needs to be considered in people with suspicious symptoms who are taking an inhaled corticosteroid, particularly when taken at higher doses, and when oral corticosteroids are taken intermittently.

\section{ACKNOWLEDGEMENTS}

The authors thank the Epidemiology and Pharmacology Information Core for providing data from the THIN database.

\section{Authors' affiliations}

K J Mortimer, T W Harrison, A E Tattersfield, Division of Respiratory Medicine, Nottingham City Hospital, Nottingham University,

Nottingham, UK

L J Tata, C J P Smith, J West, R B Hubbard, Division of Epidemiology and Public Health, Nottingham University, Nottingham, UK

The Department of Respiratory Medicine has previously received financial support for clinical research from AstraZeneca and GlaxoSmithKline. There was no specific source of funding for this study.

\section{REFERENCES}

1 Treadwell BL, Savage O, Sever ED, et al. Pituitary-adrenal function during corticosteroid therapy. Lancet 1963;1:355-8.

2 Livanou T, Ferriman D, James VHT. Recovery of hypothalamo-pituitaryadrenal function after corticosteroid therapy. Lancet 1967;2:856-9.

3 Robinson BHD, Mattingly D, Cope CL. Adrenal function after prolonged corticosteroid therapy. BMJ 1962;1:1579-84.

4 Todd GRG, Acerini CL, Ross-Russell R, et al. Survey of adrenal crisis associated with inhaled corticosteroids in the United Kingdom. Arch Dis Child 2002;87:457-61

5 Todd GRG. Adrenal crisis due to inhaled steroids is underestimated. Arch Dis Child 2003;88:554-5.

6 World Health Organisation. Fluticasone and adrenal crisis. WHO Drug Information 2003;17:92.

7 Barton K. Fluticasone and adrenal suppression. Can Adverse Reaction Newsletter 2003;13:2.

8 White A, Woodmansee DP. Adrenal insufficiency from inhaled corticosteroids. Ann Intern Med 2004;140:W27.

9 Bourke A, Dattani H, Robinson M. Feasibility study and methodology to create a quality-evaluated database of primary care data. Inform Prim Care 2004; 12:171-7.

10 Walley T. The UK General Practice Database. Lancet 1997;350:1097-9.

11 Brown M, Storey G, George WHS. Beclometasone dipropionate: a new steroid aerosol for the treatment of allergic asthma. BMJ 1972;1:585-90.

12 Maberley DJ, Gibson GJ, Butler AG. Recovery of adrenal function after substitution of beclomethasone dipropionate for oral corticosteroids. BMJ 1973;1:778-82.

13 Batten JC, Clarke SW, Gregg I, et al. Corticosteroid withdrawal in asthma. BMJ 1973;1:296.

14 Cayton RH, Howard P. Adrenal failure in bronchial asthma. BMJ 1973;2:547.

15 Patel L, Wales JK, Kibirige MS, et al. Symptomatic adrenal insufficiency during inhaled corticosteroid treatment. Arch Dis Child 2001;85:330-4.

16 Wong J, Black P. Acute adrenal insufficiency associated with high dose inhaled steroids. BMJ 1992;304:1415.

17 Zwaan CM, Odink RJH, Delemarre-van de Waal HA, et al. Acute adrenal insufficiency after discontinuation of inhaled corticosteroid therapy. Lancet 1992;340:1289-90.

18 Drake AJ, Howells RJ, Shield JPH, et al. Symptomatic adrenal insufficiency presenting with hypoglycaemia in children with asthma receiving high dose inhaled fluticasone propionate. BMJ 2002;324:1081-2.

19 Todd GRG, Wright D, Ryan M. Acute adrenal insufficiency in a patient with asthma after changing from fluticasone propionate to budesonide. J Allergy Clin Immunol 1999;103:956-7.

20 Duplantier JE, Nelson RP, Morelli AR, et al. Hypothalamic-pituitary-adrenal axis suppression associated with the use of inhaled fluticasone propionate. J Allergy Clin Immunol 1998; 102:699-700.

21 Dunlop KA, Carson DJ, Shields MD. Hypoglycemia due to adrenal suppression secondary to high-dose nebulized corticosteroid. Pediatr Pulmonol 2002;34:85-6.

22 Albert SG, Slavin RG. Adrenal insufficiency in an adult on inhaled corticosteroids; recovery of adrenal function with inhaled nedocromil sodium. Ann Allergy Asthma Immunol 1998;81:582-4.

23 Todd GRG, Acerini CL, Buck JJ, et al. Acute adrenal crisis in asthmatics treated with high-dose fluticasone propionate. Eur Respir J 2002;19:1207-9.

24 Barnes N. Relative safety and efficacy of inhaled corticosteroids. J Allergy Clin Immunol 1998;101:S460-4.

25 Harrison TW, Tattersfield AE. Plasma concentrations of fluticasone propionate and budesonide following inhalation from dry powder inhalers by healthy and asthmatic subjects. Thorax 2003;58:258-60. 